\title{
The relation of multiple-schedule behavioral contrast to deprivation, time in session, and within-session changes in responding
}

\author{
FRANCES K. MCSWEENEY, SAMANTHA SWINDELL, ERIC S. MURPHY, and BENJAMIN P. KOWAL \\ Washington State University, Pullman, Washington
}

\begin{abstract}
Pigeons' keypecking was reinforced by food on baseline schedules of multiple variable interval (VI) $x$ VI $x$ and on contrast schedules of multiple VI $x$ VI $y$. Deprivation of food was varied by maintaining subjects at $75 \%, 85 \%$, and $95 \%$ ( $\pm 2 \%)$ of their free-feeding weights. Positive and negative behavioral contrast were observed. The size of the contrast was not systematically altered by changes in deprivation. Positive and negative contrast were both larger later in the session than they were earlier. Withinsession decreases in responding were steeper for the baseline than for the contrast schedules for positive contrast. Within-session decreases were steeper for the contrast than for the baseline schedules for negative contrast. These results were predicted by the idea that different amounts of habituation to the reinforcer during the baseline and contrast schedules contribute to behavioral contrast. The results show that contrast occurs under conditions that reduce the effect of the following component. The results support the assumption that positive and negative contrast are produced by symmetrical theoretical variables.
\end{abstract}

Multiple-schedule behavioral contrast is usually studied by comparing the rate of responding during a baseline schedule that provides the same conditions of reinforcement in both components (e.g., a multiple variable interval [VI $x$ ] VI $x$ schedule) with responding during a contrast schedule that provides different conditions of reinforcement in the two components (e.g., a multiple VI $x$ VI $y$ schedule; McSweeney \& Norman, 1979). Positive contrast occurs if response rate in the VI $x$ component increases from the baseline to the contrast phase when the VI $y$ schedule provides poorer conditions of reinforcement than the VI $x$ schedule (e.g., a lower rate of reinforcement). Negative contrast occurs if response rate in the VI $x$ component decreases from the baseline to the contrast phase when the VI $y$ schedule provides better conditions of reinforcement than the VI $x$ schedule (e.g., a higher rate of reinforcement). Throughout this article, the component that is changed to produce contrast will be called the variable component; the component that is held constant will be called the constant component.

Understanding behavioral contrast is important because contrast has many fundamental theoretical and applied implications. At the theoretical level, contrast implies that reinforcers have a relative, rather than an absolute, effect on behavior (e.g., Herrnstein, 1970). That is, reinforcer ef-

The conduct of these experiments and the preparation of this article were partially supported by Grant RO1 MH6170 from the National Institute of Mental Health to F.K.M. Some of the results were part of a dissertation submitted in partial completion of a Ph.D. degree by S.S. Correspondence concerning this article should be addressed to F. K. McSweeney, Department of Psychology, Washington State University, Pullman, WA 99164-4820 (e-mail: fkmcs@mail.wsu.edu). fectiveness is not a constant. Instead, it varies inversely with the value of other reinforcers that are also available in the same situation. At an applied level, behavioral contrast may oppose efforts to change behavior (e.g., Gross \& Drabman, 1981). If a therapist tries to increase the frequency of a behavior by increasing reinforcement in one situation, contrast may reduce the frequency of the behavior in other situations, a potentially undesirable result.

Despite the importance of contrast, no one theory has been generally accepted. Recently, McSweeney and Weatherly (1998) proposed a new theory. They argued that multipleschedule behavioral contrast is produced partially by habituation to the sensory properties of the reinforcers as those reinforcers are presented repeatedly in the experimental session (e.g., McSweeney, Hinson, \& Cannon, 1996). Habituation is a decrease in responsiveness to a stimulus that is presented repeatedly or for a prolonged time (e.g., Thompson \& Spencer, 1966). It is often assumed to be the simplest learning process and to occur for most, if not all, species (e.g., Harris, 1943; Thorpe, 1966). Habituation was sometimes restricted to reflexive or nonassociative behavior and to stimuli that lacked biological significance. However, more recent research has shown that habituation may be associative (e.g., Wagner, 1976), occurs for complex behaviors (e.g., Poucet, Durup, \& Thinus-Blanc, 1988), and occurs for biologically significant stimuli (e.g., food; Swithers \& Hall, 1994). Therefore, habituation may reduce responsiveness to, and therefore the effectiveness of, stimuli (including reinforcers) presented during operant conditioning procedures.

According to McSweeney and Weatherly's (1998) theory, reducing the rate of reinforcement in one component of a multiple schedule reduces the amount of habituation 
that occurs to the reinforcer during the experimental session (e.g., McSweeney, 1992). As a result, the reinforcers provided in the other component are more effective (less habituation) and support a higher rate of responding (positive contrast). Likewise, providing more reinforcers in one component increases habituation to the reinforcer, reducing the effectiveness of other-component reinforcers. Less effective reinforcers support a lower rate of responding (negative contrast).

To illustrate, suppose that the baseline is a multiple VI 60 -sec VI 60-sec schedule that delivers a maximum of 60 reinforcers per hour on the average. Positive contrast could be produced by changing this baseline schedule to a multiple VI $60-\mathrm{sec}$ extinction schedule that delivers approximately 30 reinforcers per hour. If each delivery of the reinforcer produces some habituation, then less habituation occurs during the contrast (30 reinforcers) than during the baseline (60 reinforcers) sessions. As a result, reinforcers delivered in the constant, VI 60-sec, component are more effective and support a higher rate of responding during the contrast than during the baseline phase (positive contrast). Negative contrast could be produced by changing the baseline to a multiple VI 60-sec VI 15 -sec schedule that delivers approximately 150 reinforcers per hour. More habituation should occur during the contrast (150 reinforcers) than during the baseline (60 reinforcers) sessions. As a result, the reinforcers delivered during the constant, VI 60-sec, component are less effective and support a lower rate of responding during the contrast than during the baseline phase (negative contrast).

The theory proposed by McSweeney and Weatherly (1998) is parsimonious, relies only on processes that have been supported by independent evidence, is compatible with much of the literature on multiple-schedule behavioral contrast (McSweeney \& Weatherly, 1998), and has made predictions that have been supported by new experiments (McSweeney, Murphy, \& Kowal, 2003). The present experiment examines several additional predictions of this theory when pigeons serve as subjects. Consideration of a related idea, that contrast is produced by differences in satiation to the reinforcer between the baseline and contrast schedules (Killeen, 1995), will be reserved for the Discussion section.

First, McSweeney and Weatherly (1998) predicted that the late-session decreases in responding in the constant component should be steeper during the baseline schedule than during the positive contrast schedule and steeper during the negative contrast schedule than during the baseline schedule. McSweeney, Hinson, and Cannon (1996) argued that late-session decreases in response rate are produced primarily by habituation to the reinforcer. More habituation produces steeper late-session decreases. If positive contrast results partly from greater habituation during the baseline than during the contrast schedule, then the late-session decrease in responding should be steeper during the baseline than during the contrast schedule for the component that is held constant across these schedules. If negative contrast results partly from greater habituation during the contrast than during the baseline schedule, then the late- session decrease should be steeper during the contrast than during the baseline schedule for the constant component.

Second, McSweeney and Weatherly (1998) predicted that the size of behavioral contrast should increase within the session for both positive and negative contrast. Habituation to the reinforcer accumulates within the session as the reinforcer is presented repeatedly. As a result, the differences in habituation between the baseline and contrast schedules that contribute to contrast should increase in size across the session.

Finally, McSweeney and Weatherly (1998) predicted that changes in deprivation for the reinforcer may not alter the size of contrast. Although this has not been studied extensively, changes in deprivation do not alter habituation to food when rats are at least 18 days old (Swithers-Mulvey, Miller, \& Hall, 1991). Changes in deprivation for food also fail to alter the form of the within-session pattern of operant responding for food when rats serve as subjects (Roll, McSweeney, Johnson, \& Weatherly, 1995). Therefore, if the results reported for rats also apply to pigeons, then the size of contrast should not change with changes in deprivation for the reinforcer.

\section{METHOD}

\section{Subjects}

The subjects were eight experimentally experienced pigeons. They were housed individually in the Johnson Tower Vivarium and experienced a 12:12-h light:dark cycle. The subjects had free access to water in their home cages but were maintained at approximately $75 \%, 85 \%$, or $95 \%$ of their free-feeding weights at different times during the experiment. Weights were maintained by postsession feedings given when all the subjects had completed the experiment for the day. If a subject differed from its target weight by more than $2 \%$, the animal was not run until it returned to target weight.

\section{Apparatus}

The apparatus was a single-key enclosure for pigeons, measuring $25.5 \times 28.0 \times 29.0 \mathrm{~cm}$. The response key was a $2.0-\mathrm{cm}$ diameter Plexiglas panel, located $7.5 \mathrm{~cm}$ below the ceiling and $3.5 \mathrm{~cm}$ from the left wall. The key operated when a force of approximately $0.25 \mathrm{~N}$ was applied to its center. A $5.5 \times 4.5$-cm opening allowed access to a hopper that contained mixed grain. The opening was $4.5 \mathrm{~cm}$ above the floor and was centered $10.0 \mathrm{~cm}$ from each wall. A $3.0 \times 2.5-\mathrm{cm}$ opaque panel served as the houselight. It was located $10.0 \mathrm{~cm}$ above the hopper. The apparatus was enclosed in a sound-attenuating chamber. A ventilating fan masked noise from outside the chamber. Experimental events were presented and data were recorded by an IBM-compatible computer connected to a Med Associates interface running MedState Software. The computer was located in a different room from the experimental enclosure.

\section{Procedure}

Because the subjects had pecked keys in previous experiments, they were immediately placed into the experimental procedure. During the baseline, all subjects responded on a multiple VI 30 -sec VI 30 -sec schedule. Red and white lights on the key signaled the components. Reinforcers were $5 \mathrm{sec}$ of access to mixed grain and were presented according to two independent 25-interval Fleshler and Hoffman (1962) series, one for each component. Components were $30 \mathrm{sec}$ long and were presented randomly, with the stipulation that one component could not be presented more than three successive times. Sessions were $60 \mathrm{~min}$ in length. The time for which reinforce- 
ment was available was excluded from the component and session times. The sessions were conducted daily, three to six times per week, for a total of 30 sessions.

During the contrast phase, 4 subjects responded on a multiple VI 30 -sec extinction (positive contrast), and 4 subjects responded on a multiple VI 30-sec VI 7.5-sec (negative contrast) schedule. For some subjects, the changed (extinction or VI 7.5-sec) component was signaled by the red light; for others, by the white light. All other procedural details were the same as those for the baseline condition. The contrast phase was in effect for 30 sessions, and then the baseline (multiple VI 30-sec VI 30-sec) schedule was restored for 30 sessions. Baseline was recovered to ensure that any change in responding from the baseline to the contrast schedule represented behavioral contrast rather than a fluctuation in response rates over time.
Each subject experienced this set of three schedules three times: at $75 \%, 85 \%$, and $95 \%( \pm 2 \%)$ of its free-feeding body weight. Target weights were calculated for each subject prior to the beginning of the experiment. The order of deprivation conditions was randomized across subjects.

The components were presented randomly, rather than alternated, to present a relatively pure test of McSweeney and Weatherly's (1998) theory. They argued that habituation is only one of several factors that may contribute to contrast. Other studies have suggested that factors related to the conditions of reinforcement in the following component also contribute (e.g., Williams, 1991). The present experiment reduced the contribution of the following conditions of reinforcement by making those conditions unpredictable through random component presentation.

Table 1

\begin{tabular}{|c|c|c|c|c|c|c|c|c|}
\hline \multirow[b]{2}{*}{ Subject } & \multicolumn{8}{|c|}{ Positive Contrast } \\
\hline & VI 30-sec & VI 30-sec & VI 30-sec & ext & VI 30-sec & VI 30-sec & Ratio & Diff \\
\hline \multicolumn{9}{|c|}{$75 \%$ Deprivation } \\
\hline 29 & 29.9 & 23.9 & 49.1 & 3.9 & 35.9 & 23.0 & 1.49 & 16.2 \\
\hline 30 & 47.6 & 30.4 & 93.5 & 3.0 & 59.9 & 28.6 & 1.74 & 39.7 \\
\hline 103 & 68.7 & 57.7 & 106.0 & 15.1 & 51.5 & 41.9 & 1.76 & 45.9 \\
\hline 592 & 54.7 & 61.7 & 115.4 & 56.4 & 46.7 & 49.2 & 2.28 & 64.7 \\
\hline$M$ & 50.2 & 43.4 & 91.0 & 19.6 & 48.5 & 35.7 & 1.84 & 41.6 \\
\hline \multicolumn{9}{|c|}{$85 \%$ Deprivation } \\
\hline 29 & 32.2 & 25.9 & 43.6 & 1.7 & 27.6 & 22.6 & 1.46 & 13.7 \\
\hline 30 & 41.0 & 45.0 & 83.9 & 26.5 & 43.3 & 36.7 & 1.99 & 41.7 \\
\hline 103 & 45.3 & 43.1 & 96.6 & 21.8 & 50.0 & 65.6 & 2.03 & 48.9 \\
\hline 592 & 37.3 & 28.8 & 94.4 & 20.6 & 45.9 & 65.7 & 2.27 & 52.8 \\
\hline$M$ & 39.0 & 35.7 & 79.6 & 17.7 & 41.7 & 47.7 & 1.97 & 39.2 \\
\hline \multicolumn{9}{|c|}{ 95\% Deprivation } \\
\hline 29 & 25.1 & 19.6 & 39.2 & 0.8 & 12.0 & 7.3 & 2.11 & 20.6 \\
\hline 30 & 25.2 & 23.6 & 70.8 & 4.2 & 32.0 & 23.3 & 2.48 & 42.2 \\
\hline 103 & 23.1 & 17.3 & 57.1 & 1.4 & 26.9 & 12.7 & 2.28 & 32.1 \\
\hline 592 & 21.0 & 21.7 & 43.8 & 9.2 & 21.8 & 20.2 & 2.05 & 22.4 \\
\hline$M$ & 23.6 & 20.6 & 52.7 & 3.9 & 23.2 & 15.9 & 2.25 & 29.3 \\
\hline
\end{tabular}

\begin{tabular}{|c|c|c|c|c|c|c|c|c|}
\hline \multirow[b]{2}{*}{ Subject } & \multicolumn{8}{|c|}{ Negative Contrast } \\
\hline & VI 30-sec & VI 30-sec & VI $30-\mathrm{sec}$ & VI 7.5-sec & VI 30-sec & VI 30-sec & Ratio & Diff \\
\hline \multicolumn{9}{|c|}{$75 \%$ Deprivation } \\
\hline 44 & 84.3 & 79.2 & 51.4 & 87.8 & 142.9 & 143.4 & 0.45 & -62.2 \\
\hline 51 & 51.1 & 52.8 & 22.0 & 37.4 & 51.6 & 43.1 & 0.43 & -29.4 \\
\hline 908 & 106.8 & 110.6 & 68.4 & 104.1 & 113.5 & 110.9 & 0.62 & -41.8 \\
\hline 912 & 62.5 & 61.7 & 59.2 & 90.1 & 69.7 & 65.4 & 0.90 & -6.9 \\
\hline$M$ & 76.2 & 76.1 & 50.3 & 79.9 & 94.4 & 90.7 & 0.59 & -35.0 \\
\hline \multicolumn{9}{|c|}{$85 \%$ Deprivation } \\
\hline 44 & 113.6 & 116.6 & 66.0 & 93.9 & 123.4 & 125.8 & 0.56 & -52.5 \\
\hline 51 & 20.1 & 21.5 & 13.7 & 28.7 & 28.1 & 28.2 & 0.57 & -10.4 \\
\hline 908 & 95.7 & 92.5 & 50.3 & 79.8 & 103.2 & 99.5 & 0.51 & -49.2 \\
\hline 912 & 46.4 & 44.0 & 20.0 & 36.9 & 53.3 & 53.5 & 0.40 & -29.9 \\
\hline$M$ & 69.0 & 68.7 & 37.5 & 59.8 & 77.0 & 76.8 & 0.51 & -35.5 \\
\hline \multicolumn{9}{|c|}{ 95\% Deprivation } \\
\hline 44 & 83.8 & 85.9 & 40.1 & 58.0 & 74.2 & 75.3 & 0.51 & -38.9 \\
\hline 51 & 23.0 & 20.1 & 17.3 & 28.1 & 35.9 & 34.7 & 0.59 & -12.2 \\
\hline 908 & 71.7 & 66.9 & 24.0 & 35.9 & 70.3 & 75.4 & 0.34 & -47.0 \\
\hline 912 & 66.6 & 55.9 & 23.2 & 39.0 & 59.8 & 47.3 & 0.37 & -40.0 \\
\hline$M$ & 61.3 & 57.2 & 26.2 & 40.3 & 60.1 & 58.2 & 0.43 & -34.5 \\
\hline
\end{tabular}

Note-Ratio (Ratio) and difference (Diff) measures of the size of contrast also appear. 

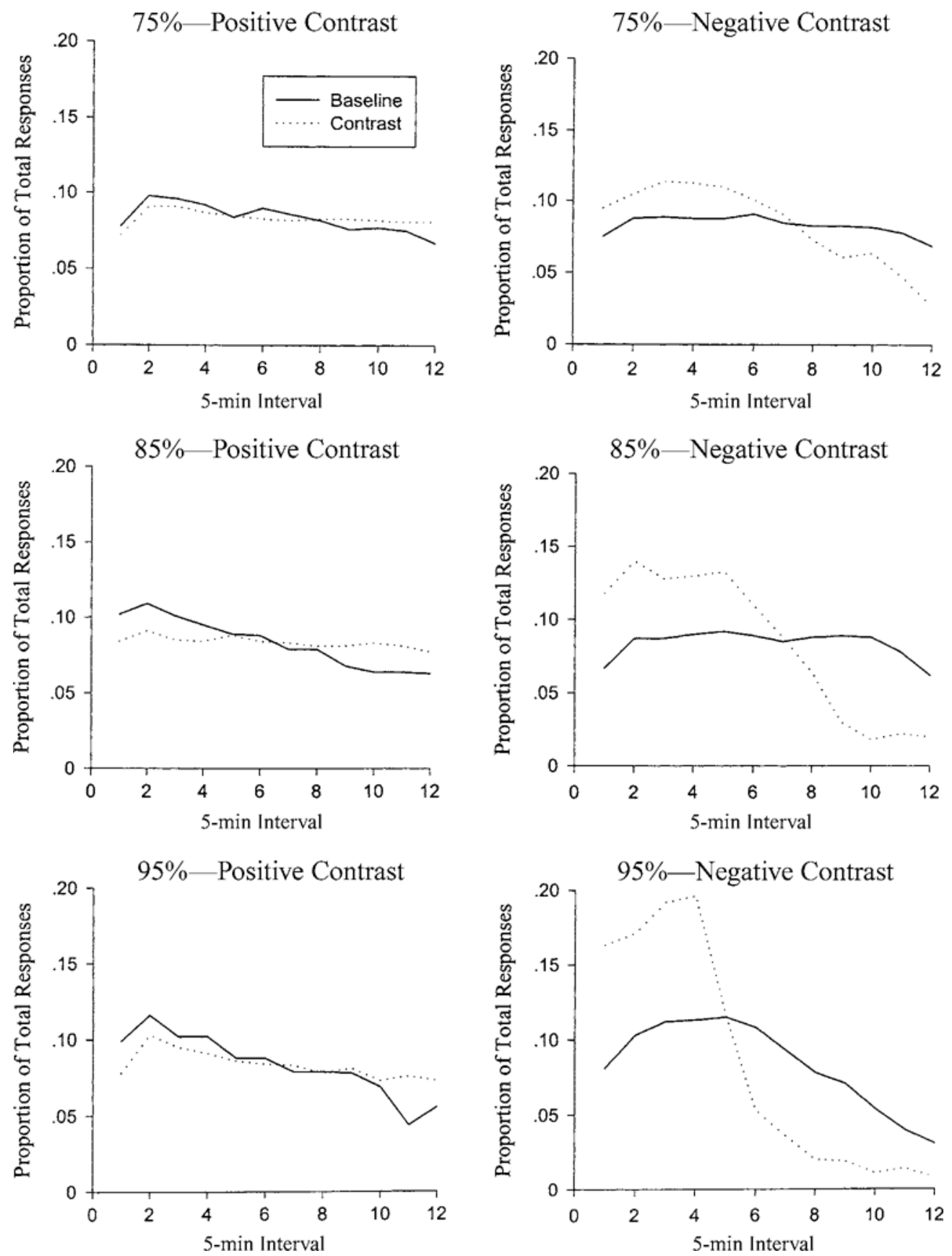

Figure 1. Proportion of total-session responses during successive 5-min intervals in the session for the mean of all pigeons responding on the constant component of the baseline (solid line) and contrast (dashed line) schedules. Each row of graphs represents the result for a different free-feeding weight. Results for positive contrast appear in the left graphs, for negative contrast in the right graphs. Results for the baseline were averaged over the two presentations of that schedule.

\section{RESULTS}

\section{Positive Contrast}

Table 1 (top) presents the rate of responding (responses per minute) averaged over the session for each pigeon, and for the mean of all pigeons, responding during each com- ponent of each baseline and contrast schedule for the positive contrast conditions. Response rates were calculated by dividing the number of responses emitted per session during a component by the time for which that component was available. The time for which the magazine was available was excluded from the calculations. Here and through- 
out this article, the results were averaged over the last five sessions for which a schedule was presented.

Table 1 also provides two measures of the size of contrast. Two measures are provided to ensure the generality of the conclusions. To calculate the difference measures (Diff), the average rate of responding during the constant component of the average baseline schedules was subtracted from the rate of responding during the same component of the contrast schedule. Differences greater than zero indicate positive contrast. To calculate the ratio measures (Ratio), the rate of responding during the constant component of the contrast schedule was divided by the average rate of responding during the same component in the baseline schedules. The results for the mean are the contrast ratios calculated by using the mean of all response rates; they are not the mean of the contrast ratios for the individual subjects. Ratios greater than 1.0 represent positive contrast.

Table 1 shows that rate of responding decreased during the variable component when the VI 30-sec schedule was replaced by extinction. Positive contrast also occurred for each subject responding at each level of deprivation. For each level of deprivation, eight comparisons can be made for individual subjects between the rate of responding during the constant components of the contrast and baseline schedule. The response rate was greater during the constant component of the contrast, than of the baseline, schedules for all eight comparisons at each level of deprivation.

Table 1 also shows that the size of positive contrast did not change with changes in deprivation in a way that was consistent over individual subjects or measures of the size of contrast. For the mean of all subjects, ratio measures increased with decreases in deprivation, but difference measures decreased with decreases in deprivation. These changes were not consistent over individual subjects. Ratio measures generally increased with decreases in deprivation for all subjects except for Subject 592. Difference measures generally increased with decreases in deprivation for Subjects 29 and 30 but generally decreased for Subjects 103 and 592. As a result, one-way (deprivation) repeated measures analyses of variance (ANOVAs) were not significant $(p<.05)$ for either the ratio $[F(2,6)=$ $2.988, p<.126]$ or the difference $[F(2,6)=1.281, p<$ .344] measures.

Figure 1 (left graphs) presents the within-session pattern of responding during the constant component of the baseline (solid lines) and contrast (dashed lines) schedules for the mean of all subjects. Each graph presents the results for a different level of deprivation. The figure presents the proportion of total-session response rates during successive 5-min intervals in the session. The proportions are presented to normalize the data for differences in absolute rates of responding (see Table 1). The proportions were calculated by dividing the rate of constant-component responding during a 5-min interval by the sum of the rates of constant-component responding during all 5-min intervals in the session. The response rates were averaged over the two presentations of the baseline schedules before the proportions were calculated. The proportions were calculated using the mean response rates; they are not the mean of the proportions for individual subjects.

Figure 1 shows that responding changed within sessions during the baseline schedules in the present experiment, as it has in the past (e.g., McSweeney, 1992). That is, the response rate during the baseline schedules increased slightly and then decreased across the session. Figure 1 also shows that, as was predicted, the late-session decreases in responding were steeper (larger decrease) during the baseline than during the contrast conditions for each level of deprivation. However, this difference was small for subjects maintained at $75 \%$ of their free-feeding weights.

Table 2 (top) shows that similar results occurred for individual subjects. It presents the size of the late-session

Table 2

Size of the Late-Session Decrease in Responding for Each Individual

Pigeon and for the Mean of All Pigeons Responding During the Constant Component of Each Baseline (B) and Contrast (C) Schedule

\begin{tabular}{|c|c|c|c|c|c|c|}
\hline \multirow[b]{3}{*}{ Subject } & \multicolumn{6}{|c|}{ Positive Contrast } \\
\hline & \multicolumn{2}{|c|}{$75 \%$} & \multicolumn{2}{|c|}{$85 \%$} & \multicolumn{2}{|c|}{$95 \%$} \\
\hline & B & $\mathrm{C}$ & B & $\mathrm{C}$ & B & $\mathrm{C}$ \\
\hline 29 & 0.008 & 0.025 & 0.009 & 0.016 & 0.054 & 0.009 \\
\hline 30 & 0.017 & 0.008 & 0.024 & 0.006 & 0.039 & 0 \\
\hline 103 & 0.048 & 0.014 & 0.030 & 0.013 & 0.075 & 0.076 \\
\hline 592 & 0.060 & 0.010 & 0.145 & 0.032 & 0.097 & 0.065 \\
\hline \multirow[t]{3}{*}{$M$} & 0.031 & 0.010 & 0.046 & 0.014 & 0.060 & 0.030 \\
\hline & \multicolumn{6}{|c|}{ Negative Contrast } \\
\hline & \multicolumn{2}{|c|}{$75 \%$} & \multicolumn{2}{|c|}{$85 \%$} & \multicolumn{2}{|c|}{$95 \%$} \\
\hline Subject & B & $\mathrm{C}$ & B & $\mathrm{C}$ & B & $\mathrm{C}$ \\
\hline 44 & 0.041 & 0.142 & 0.018 & 0.165 & 0.146 & 0.243 \\
\hline 51 & 0.042 & 0.104 & 0.078 & 0.179 & 0.096 & 0.143 \\
\hline 908 & 0.018 & 0.129 & 0.038 & 0.084 & 0.109 & 0.281 \\
\hline 912 & 0.000 & 0.025 & 0.047 & 0.215 & 0.015 & 0.181 \\
\hline$M$ & 0.022 & 0.087 & 0.030 & 0.120 & 0.084 & 0.188 \\
\hline
\end{tabular}

Note-Results for the baseline were averaged over the two presentations of this schedule. 

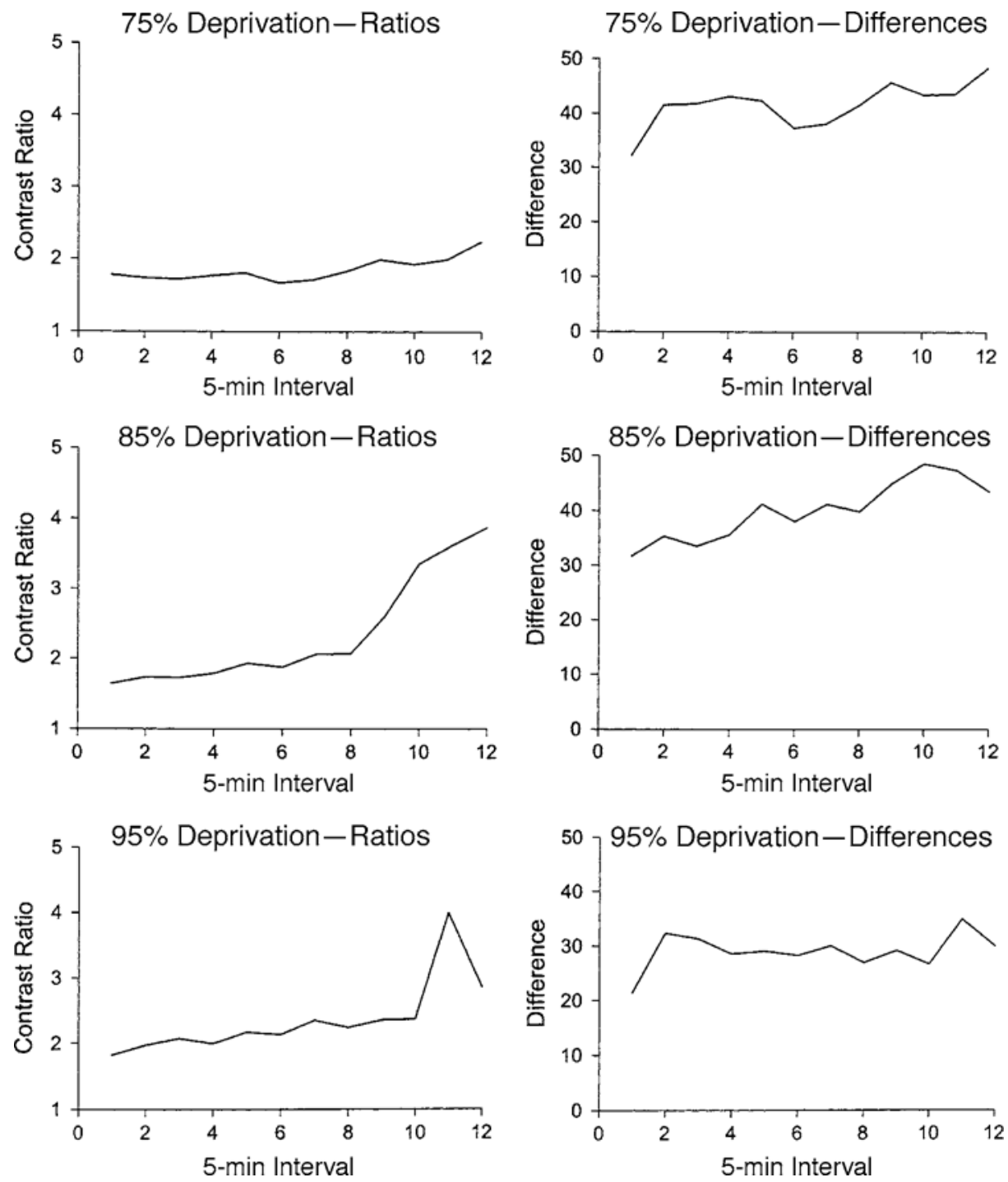

Figure 2. Within-session changes in the size of positive contrast for the mean of all pigeons. Each row of graphs presents the results for a different free-feeding weight. The left graphs present contrast measured by ratios; the right graphs present contrast measured by differences. The calculation of these measures is described in the text.

decreases in responding for the constant component of the averaged baselines and the contrast schedules for individual subjects responding at each level of deprivation. The size of the decrease was calculated by subtracting the proportion of total responding during the last 5-min interval from the proportion of total responding during the 5-min interval in which responding was fastest (peak - last). The late-session decreases in responding were larger for the baseline than for the contrast conditions for all subjects at all deprivations except for Subject 29 responding at $75 \%$ and $85 \%$ of its free-feeding weight and for Subject 103 responding at $95 \%$ of its free-feeding weight.

Figure 2 presents within-session changes in the size of positive contrast measured by contrast ratios (left graphs) or differences (right graphs). Each graph in a column represents the results for a different deprivation. Ratios and differences were calculated in the same way as they were for Table 1 except that they were calculated over 5-min intervals, rather than over the entire session. Figure 2 shows that the size of positive contrast generally increased across the session for all deprivations, regardless of whether size was measured by differences or ratios.

\section{Negative Contrast}

Table 1 (bottom) presents the rate of responding (responses per minute) averaged over the session for each pigeon, and for the mean of all pigeons, responding during each component of each baseline and contrast schedule 
for the negative contrast conditions. The results were calculated and presented in the same way as they were for positive contrast. Contrast ratios less than 1.0, and contrast differences less than zero, represent negative contrast. Table 1 shows that the rate of responding in the variable component sometimes declined when the VI 7.5-sec schedule replaced the VI 30-sec schedule. Decreases in rates of responding at very high rates of reinforcement are often observed (see McSweeney \& Hinson, 1992, for a discussion) and are predicted by several theories (e.g., Baum, 1981; Staddon, 1979). Table 1 also shows that negative contrast, defined as a decrease in response rate during the constant component of a multiple schedule with improvements in the conditions of reinforcement in the other component (e.g., McSweeney \& Norman, 1979), occurred for all the subjects. The rate of responding during the constant component of the contrast schedule was less than the rate in the comparable component of the two baselines for eight of eight comparisons for individual subjects responding at each percentage of body weight. As a result, all of the ratio and difference measures indicated that negative contrast occurred.

As for positive contrast, the size of negative contrast did not vary systematically with deprivation. For the mean of all subjects, contrast ratios became smaller (indicating larger negative contrast) with decreases in deprivation. Difference measures were remarkably constant across deprivations (difference measures $=-35.0,-35.5$, and -34.5 for the $75 \%, 85 \%$, and $95 \%$ deprivations, respectively). Again, however, changes in the size of contrast with changes in deprivation differed for different subjects. The size of the contrast ratios generally increased toward 1.0 (indicating a decrease in the size of negative contrast) with decreases in deprivation for Subjects 44 and 51. The size of the contrast ratios decreased (indicating an increase in the size of negative contrast) with decreases in deprivation for Subjects 908 and 912. The absolute size of the contrast differences generally decreased (indicating a decrease in the size of negative contrast) with increases in deprivation for Subjects 44 and 51. The absolute size of the differences generally increased (indicating an increase in the size of negative contrast) with decreases in deprivation for Subjects 908 and 912. As a result, one-way (deprivation) repeated measures ANOVAs were not significant for either the ratio $[F(2,6)=0.683, p<.540]$ or the difference $[F(2,6)=0.005, p<.995]$ measures.

Figure 1 (right graphs) presents the within-session response patterns during the constant component of the baseline (solid line) and contrast (dashed line) schedules for the mean of all pigeons. The results were calculated in the same way as those for positive contrast. Figure 1 shows that, as was predicted, the within-session decreases in responding were larger when the subjects responded on the contrast than on the baseline schedules.

Table 2 (bottom) shows that similar results were found for individual subjects. It presents the size of the latesession decreases in responding for the constant compo- nent of the averaged baselines and the contrast schedules for individual pigeons responding at each level of deprivation. The results were calculated and presented in the same way as those for positive contrast. The late-session decreases in responding were larger for the contrast than for the baseline conditions for all subjects at all deprivations.

Figure 3 presents within-session changes in the size of contrast measured by contrast ratios (left graphs) and differences (right graphs). The results were calculated and presented in the same way as those for Figure 2. Figure 3 shows that the size of negative contrast generally increased across the session for all deprivations, regardless of whether size was measured by differences or ratios. Both measures of contrast decreased again late in the session for pigeons responding at $95 \%$ of their free-feeding weight. Difference measures of contrast decreased late in the session for pigeons responding at $85 \%$.

Figure 4 presents absolute rates of responding (left graphs) and proportion of total-session responses (right graphs) during successive 5-min intervals in the session for the mean of all pigeons responding during the averaged baselines for each deprivation. The top graphs present results for the positive contrast conditions; the bottom graphs present results for the negative contrast conditions. The figure shows that, similar to the results of past studies (e.g., Clark, 1958), the subjects responded more quickly when maintained at $75 \%$ body weight than when maintained at $85 \%$. The subjects also responded more quickly when maintained at $85 \%$ than at $95 \%$ weight. In agreement with past results (Roll et al., 1995), the top graphs also show that the within-session response patterns were similar for different deprivations when proportions normalized the data for differences in absolute response rates in the positive contrast conditions. Unlike past results, the bottom graphs show that the within-session change in responding was larger when the subjects were maintained at $95 \%$ of their free-feeding weights than when they were maintained at $75 \%$ or $85 \%$ weights in the negative contrast conditions.

\section{DISCUSSION}

The present results showed that the absolute sizes of both positive and negative contrast increased with time in the session; that positive contrast was accompanied by steeper late-session decreases in responding during the baseline schedule than during the contrast schedule; that negative contrast was accompanied by steeper late-session decreases in responding during the contrast schedule than during baseline; and that the size of multiple-schedule contrast did not change with changes in deprivation for the reinforcer. Although the last finding is a null result, it is relatively strongly supported. Similar results were reported for both positive and negative contrast and for two different measures of the size of contrast (ratios and differences). The null result cannot be attributed to an insensitivity of the subjects to the manipulation of deprivation. 

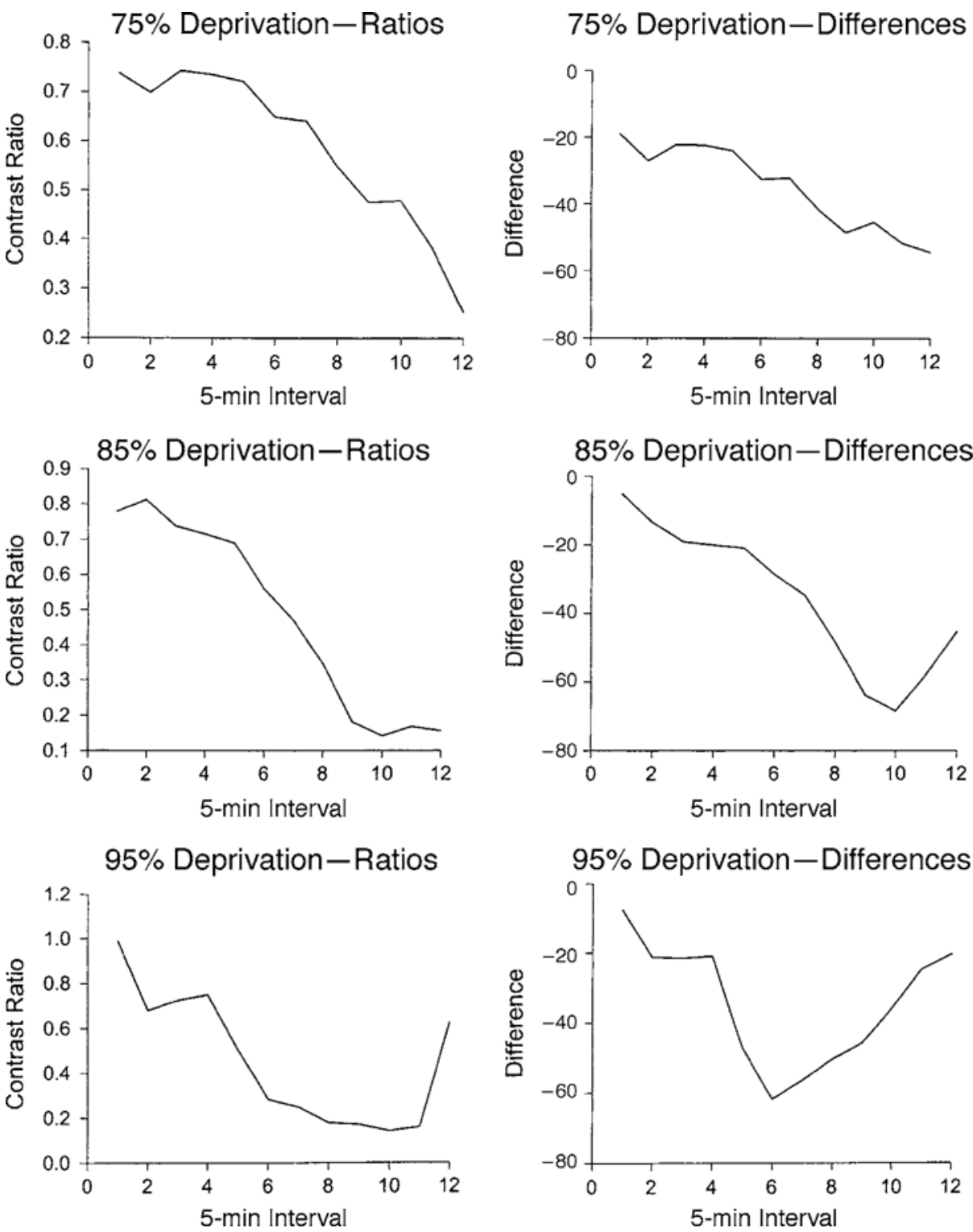

Figure 3. Within-session changes in the size of negative contrast for the mean of all pigeons. Each row of graphs presents the results for a different free-feeding weight. The left graphs present contrast measured by ratios; the right graphs present contrast measured by differences. The calculation of these measures is described in the text.

Absolute response rates changed systematically with changes in deprivation, as has been reported in past studies (e.g., Clark, 1958; see Figure 4). The null result probably cannot be attributed to using too few subjects to detect a significant change. Contrast changed in different ways with deprivation for different subjects. Therefore, running more subjects likely would not yield a significant effect of deprivation.

These results are generally consistent with McSweeney and Weatherly's (1998) theory of contrast. First, as they have argued, habituation to food may not change with changes in deprivation when adult rats serve as subjects (Swithers-Mulvey et al., 1991). Therefore, if differences in habituation contribute to contrast, as McSweeney and Weatherly argued, and if results reported for rats also occur for pigeons, then the size of contrast might not change with changes in deprivation. This was observed.

Second, McSweeney and Weatherly's (1998) theory predicts that more habituation should occur during the baseline schedule than during the positive contrast schedule and that more habituation should occur during the negative contrast schedule than during the baseline sched- 

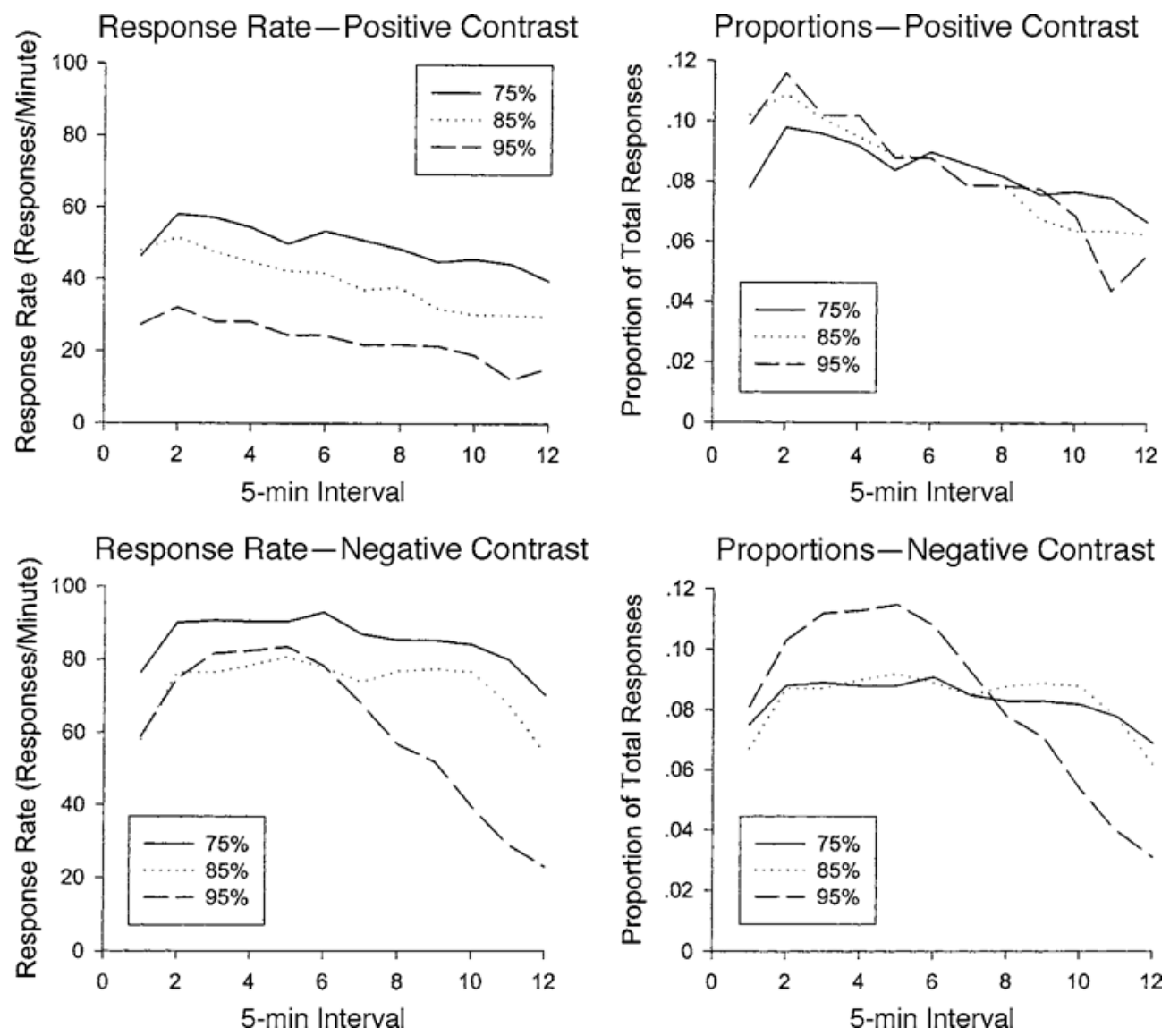

Figure 4. Within-session changes in absolute response rates (left graphs) and proportion of total-session responses (right graphs). Results are those for the mean of all pigeons, averaged over the two baselines, for the positive (top graphs) and negative (bottom graphs) contrast conditions. Each function presents the results for a different deprivation.

ule. McSweeney, Hinson, and Cannon (1996) argued that the steepness of the late-session decreases in responding represents the amount of habituation to the reinforcer that occurs within the session. In agreement with these predictions, within-session decreases in constant-component responding were steeper for the baseline than for the contrast schedules for all three deprivations in the positive contrast conditions. The decreases in constant-component responding were steeper for the contrast than for the baseline schedule for all three deprivations in the negative contrast conditions. These changes in within-sessions response patterns may be thought of as providing independent evidence for the changes in habituation from the baseline to the contrast schedule to which McSweeney and Weatherly attribute some multiple-schedule behavioral contrast.

Third, McSweeney and Weatherly (1998) predicted that differences in habituation between the baseline and contrast schedules should increase as the session passes. Because these differences contribute to contrast, the size of contrast should increase across the session. This was found for both positive and negative contrast. However, the size of contrast also decreased again late in the session when subjects were maintained at $95 \%$ deprivation, as well as when they were maintained at $85 \%$ and differences were used to measure contrast. McSweeney and Weatherly's theory did not predict such a decrease. Although these decreases should be replicated before they are taken seriously, they might eventually challenge the theory.

Several authors (e.g., Bizo, Bogdanov, \& Killeen, 1998; DeMarse, Killeen, \& Baker, 1999; Hinson \& Tennison, 1999; Palya \& Walter, 1997) have argued that withinsession patterns of responding are produced by changes in satiation for the reinforcer rather than by changes in habituation to the reinforcer. As was argued earlier, habituation is a decrease in responsiveness to a stimulus that is presented repeatedly or for a prolonged time (e.g., Groves \& Thompson, 1970; Thompson \& Spencer, 1966). The term satiation usually refers to the termination of ingestive behaviors such as feeding and drinking (e.g., Strubbe $\&$ van Dijk, 2002). The factors that contribute to that termination are called satiety factors. To give an abbreviated list, satiety factors for food include oral stimulation, distension of the stomach, distension of the duodenum, increases in blood sugar level at the liver, and increases in 
cholecystokinin (CCK) in the blood (Mook, 1996). To complicate matters, habituation to the sensory properties of food is one of the oral factors that contribute to satiation for food (e.g., Swithers \& Hall, 1994). Therefore, habituation is one among many satiety factors.

On the surface, the present results may seem to be as compatible with the idea that satiation produces the difference in the within-session patterns of responding between the baseline and contrast schedules (Killeen, 1995) as they are with the idea that habituation produces these differences (McSweeney \& Weatherly, 1998). We describe the present results as habituation, rather than satiation, for three reasons.

First, strong evidence suggests that habituation provides a better description than satiation for within-session changes in operant responding. This evidence has been reviewed elsewhere (McSweeney \& Murphy, 2000; McSweeney \& Roll, 1998). To summarize briefly, the empirical properties of within-session changes in operant responding are strongly consistent with the empirical properties of behavior undergoing habituation. Withinsession changes in operant responding show at least 11 of the generally accepted characteristics of behavior undergoing habituation (e.g., McSweeney \& Murphy, 2000). In contrast, the empirical properties of within-session changes in responding are not consistent with the action of satiety factors other than habituation. To give some examples, within-session decreases in responding are sometimes steeper for lower calorie reinforcers than they are for higher ones (e.g., Melville, Rue, Rybiski, \& Weatherly, 1997). This is inconsistent with a contribution of the satiety factor, blood sugar level. Increasing the caloric content of food should increase blood sugar levels and result in a faster termination of feeding for calorie-regulating animals, such as rats or humans (Adolph, 1947; Hausmann, 1933). In contrast, Melville et al.'s finding is consistent with habituation on the assumption that higher calorie foods sometimes provide more intense stimuli than lower calorie foods. Habituation is sometimes faster for less intense than for more intense stimuli (Thompson \& Spencer, 1966).

Within-session decreases in responding may be steeper when reinforcers are delivered on fixed ratio (FR) rather than on variable ratio (VR) schedules, even when the two schedules provide the same amounts of food (Aoyama \& McSweeney, 2001b; see also Ernst \& Epstein, 2002). This finding is not consistent with nonhabituation satiety factors because stomach distension, blood sugar levels, and so forth should be constant when food is constant. In contrast, habituation is often slower when stimuli are presented in a variable (VR), rather than in a fixed (FR), manner (e.g., Broster \& Rankin, 1994).

Changing the reinforcer for a brief time late in the session increases the response rate once the original reinforcer is restored (Aoyama \& McSweeney, 2001a; McSweeney $\&$ Roll, 1998). The response rate increases regardless of whether the change is an increase or a decrease in the amount of reinforcer delivered and regardless of whether the change produces an increase or a decrease in response rate while it is in effect. The increase in response rate is compatible with habituation because dishabituation is a fundamental property of behavior undergoing habituation. Dishabituation refers to an increase in responsiveness to a habituated stimulus after the introduction of a strong, different, or extra stimulus (e.g., Thompson \& Spencer, 1966). The increase in response rate is not consistent with the action of other satiety variables (e.g., blood sugar levels or stomach distension). Providing more reinforcers should decrease, not increase, responding by producing more satiation (e.g., higher blood sugar levels or more stomach distension). Taken together, the empirical evidence strongly supports the idea that habituation provides a better description than satiation of within-session changes in responding.

Second, other evidence about multiple-schedule behavioral contrast seems more consistent with a contribution of habituation than with a contribution of satiation. For example, McSweeney, Murphy, and Kowal (2003) reported that response rate increased during the constant, VI $x$, component when a multiple VI $x$ VI $x$ schedule was changed to a multiple VI $x$ fixed interval (FI) $x$ schedule. Constant-component responding also increased when a multiple FI $x$ FI $x$ schedule was changed to a multiple VI $x$ FI $x$ schedule. McSweeney and Weatherly's (1998) theory predicts these results. The change in the conditions of reinforcement that occurs with component transitions during the multiple VI $x$ FI $x$, but not during the multiple VI $x$ VI $x$ or the multiple FI $x$ FI $x$ schedules, should produce dishabituation (e.g., Thompson \& Spencer, 1966). Dishabituation should increase the value of the reinforcers during the multiple VI $x$ FI $x$ schedules, relative to their values during the multiple VI $x$ VI $x$ and multiple FI $x$ FI $x$ schedules, and constant-component response rates should increase. Alternative theories of contrast, including the idea that satiety contributes to contrast, do not predict these results (see McSweeney, Murphy, \& Kowal, 2003). Again, satiety factors such as stomach distension and blood sugar levels should be constant across all of these schedules because the reinforcers (amount of food) obtained from the schedules was constant.

Finally, the present failure to find an effect of deprivation on the size of contrast may question whether satiation contributes to contrast. Many studies, using several species of subjects, show that deprivation alters the rate of satiation. That is, they show that deprivation alters the rate of decline in feeding during a meal (e.g., Aoyama, 2000; Bousfield, 1935; Bousfield \& Elliott, 1934; Kissileff \& Thornton, 1982; Savory, 1988). If differences in satiation between the baseline and contrast schedules contribute to contrast, it seems likely that changes in deprivation would alter the size of contrast. Contrast would remain constant across deprivations only if the changes in deprivations altered the satiety curves in such a way that the relation between satiety in the baseline and contrast schedules remained constant across deprivations. Although this is possible, it seems unlikely. 
The effect of deprivation on within-session response patterns requires more study. The results reported in Figure 4 are both consistent with, and different from, results reported by Branch, Saulsgiver, and Pinkston (2002) and by Saulsgiver, Pinkston, and Branch (2003). These studies failed to find systematic within-session changes in operant responding when pigeons, maintained at $80 \%$ of their free-feeding weights, responded for food delivered by a VI 30 -sec schedule. Systematic within-session changes in responding were observed only when the pigeons' weights were allowed to increase from $80 \%$. The results reported by Branch and his colleagues are inconsistent with past reports of within-session changes in responding for food when subjects are maintained at $80 \%$ or less of their freefeeding weights (e.g., Palya \& Walter, 1997; Roll et al., 1995). Their results are also inconsistent with the results reported in Figure 4 for positive contrast. Large withinsession changes in responding were reported even when subjects responded at $75 \%$ weight. In addition, similar to the results reported by Roll et al. (1995), the present within-session response pattern was not altered by deprivation in the positive contrast conditions. However, the negative contrast results reported in Figure 4 provide some support for Branch's results. Within-session changes in responding were somewhat flatter when subjects were maintained at higher (75\% and $85 \%$ weights) than at lower $(95 \%$ weights) deprivations. Although, again inconsistent with Branch's results, within-session changes in responding were reported for all deprivations. The reasons for the different effect of deprivation in different studies are not known.

The present results question one strongly held assumption about behavioral contrast. Many assume that multipleschedule contrast is produced mainly by the conditions of reinforcement in the following component (e.g., Williams, 1983). Somewhat inconsistent with this idea, large and reliable positive and negative contrast were observed in the present experiment even when the contribution of the following conditions of reinforcement was reduced by random component presentation.

The present results support another assumption about contrast. Most theories assume that positive and negative contrast are produced by symmetrical factors (e.g., Hearst \& Jenkins, 1974; Herrnstein, 1970; Hinson \& Staddon, 1978; McLean, 1992; McSweeney, 1987; McSweeney \& Weatherly, 1998; Rachlin, 1973). That is, the theories attribute both positive and negative contrast to a single theoretical variable. Changes in that variable in one direction produce positive contrast. Changes in the other direction produce negative contrast. This assumption is supported by few data because negative contrast is rarely studied. The present results provide some needed support. Similar results were reported for positive and negative contrast throughout this article, supporting a common explanation for these two types of contrast.

The present experiment showed how the simple idea that habituation occurs to repeatedly presented reinforcers may contribute to understanding multiple-schedule be- havioral contrast (see also McSweeney, Murphy, \& Kowal, 2003). Future experiments are needed to assess the size and importance of this contribution. Habituation to the reinforcer may also contribute to understanding a number of other phenomena in the conditioning literature. Although habituation probably does not contribute to the preference for variability (McSweeney, Kowal, \& Murphy, 2003), it may contribute to understanding extinction (McSweeney \& Swindell, 2002; McSweeney, Swindell, \& Weatherly, 1999), behavioral economics (McSweeney \& Swindell, 1999a; McSweeney, Swindell, \& Weatherly, 1996), and the sometimes bitonic relation between response rate and rate of reinforcement (e.g., McSweeney, 1992). Habituation may also provide a single, parsimonious contributor to the termination of a variety of behaviors that are usually attributed to different factors. For example, the termination of ingestive behaviors (e.g., feeding and drinking) is usually attributed to satiation (e.g., Bizo et al., 1998); the termination of energetic behaviors (e.g., running) to fatigue (e.g., Belke, 1997); the termination of cognitive behaviors (e.g., studying) to the waning of attention (e.g., Hinson \& Tennison, 1999); and the termination of drug taking to pharmacodynamic factors (e.g., obtaining a particular high; Ahmed \& Koob, 1999). McSweeney and Swindell (1999b; see also Aoyama \& McSweeney, 2001a; Swithers \& Hall, 1994) have argued that, instead, habituation may contribute to the termination of all of these behaviors. Therefore, this simple idea may eventually prove critical to explaining a number of puzzling phenomena.

\section{REFERENCES}

Adolph, E. F. (1947). Urges to eat and drink in rats. American Journal of Physiology, 151, 110-125.

Ahmed, S. H., \& Коов, G. F. (1999). Long-lasting increase in the set point for cocaine self-administration after escalation in rats. Psychopharmacology, 146, 303-312.

AOYAMA, K. (2000). Effects of hunger state on within-session response decreases under CRF schedule. Learning \& Motivation, 31, 1-20.

Aoyama, K., \& McSweeney, F. K. (2001a). Habituation contributes to within-session changes in free wheel running. Journal of the Experimental Analysis of Behavior, 76, 289-302.

AoyAma, K., \& McSweEnEy, F. K. (2001b). Habituation may contribute to within-session decreases in responding under high-rate schedules of reinforcement. Animal Learning \& Behavior, 29, 79-91.

BAum, W. M. (1981). Optimization and the matching law as accounts of instrumental behavior. Journal of the Experimental Analysis of Behavior, 36, 387-403.

BELKE, T. W. (1997). Running and responding reinforced by the opportunity to run: Effect of reinforcer duration. Journal of the Experimental Analysis of Behavior, 67, 337-351.

Bizo, L. A., Bogdanov, S. V., \& KilleEN, P. R. (1998). Satiation causes within-session decreases in instrumental responding. Journal of Experimental Psychology: Animal Behavior Processes, 24, 439-452.

BousfiELD, W. A. (1935). Quantitative indices of the effects of fasting on eating-behavior. Journal of Genetic Psychology, 46, 476-479.

Bousfield, W. A., \& Elliott, M. H. (1934). The effect of fasting on the eating-behavior of rats. Journal of Genetic Psychology, 45, 227-237.

Branch, M. N., Saulsgiver, K. A., \& Pinkston, J. W. (2002, November). Some examinations of within-session changes in free-operant responding by pigeons. Paper presented at the meeting of the Psychonomic Society, Kansas City, MO. 
Broster, B. S., \& Rankin, C. H. (1994). Effects of changing interstimulus interval during habituation in Caenorhabditis elegans. Behavioral Neuroscience, 108, 1019-1029.

Clark, F. C. (1958). The effect of deprivation and frequency of reinforcement on variable-interval responding. Journal of the Experimental Analysis of Behavior, 1, 221-228.

DeMarse, T. B., Killeen, P. R., \& BaKer, D. (1999). Satiation, capacity, and within-session responding. Journal of the Experimental Analysis of Behavior, 72, 407-423.

ERNST, M. M., \& EPSTEIN, L. H. (2002). Habituation of responding for food in humans. Appetite, 38, 224-234.

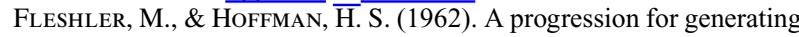
variable-interval schedules. Journal of the Experimental Analysis of Behavior, 5, 529-530.

Gross, A. M., \& DraBMAn, R. S. (1981). Behavioral contrast and behavior therapy. Behavior Therapy, 12, 231-246.

Groves, P. M., \& Thompson, R. F. (1970). Habituation: A dual-process theory. Psychological Review, 77, 419-450.

HaRris, J. D. (1943). Habituatory response decrement in the intact organism. Psychological Bulletin, 40, 385-422.

HAUSMANN, M. F. (1933). The behavior of albino rats in choosing foods: II. Differentiation between sugar and saccharin. Journal of Comparative Psychology, 15, 419-428.

Hearst, E., \& Jenkins, H. M. (1974). Sign-tracking: The stimulusreinforcer relation and directed action. Austin, TX: Psychonomic Society.

Herrnstein, R. J. (1970). On the law of effect. Journal of the Experimental Analysis of Behavior, 13, 243-266.

Hinson, J. M., \& STADDON, J. E. R. (1978). Behavioral competition: A mechanism for schedule interactions. Science, 202, 432-434.

Hinson, J. M., \& Tennison, L. R. (1999). Within-session analysis of visual discrimination. Journal of the Experimental Analysis of Behavior, 72, 385-405.

KILLEEN, P. R. (1995). Economics, ecologics, and mechanics: The dynamics of responding under conditions of varying motivation. Journal of the Experimental Analysis of Behavior, 64, 405-431.

KISSILEFF, H. R., \& THORNTON, J. (1982). Facilitation and inhibition in the cumulative food intake curve in man. In A. R. Morrison \& P. L. Strick (Eds.), Changing concepts of the nervous system: Proceedings of the First Institute of Neurological Sciences Symposium in Neurobiology (pp. 585-607). New York: Academic Press.

MCLEAN, A. P. (1992). Contrast and reallocation of extraneous reinforcers between multiple-schedule components. Journal of the Experimental Analysis of Behavior, 58, 497-511.

MCSWEenEy, F. K. (1987). Suppression by reinforcement: A model for multiple-schedule behavioral contrast. Behavioural Processes, 15, 191-209.

McSweEney, F. K. (1992). Rate of reinforcement and session duration as determinants of within-session patterns of responding. Animal Learning \& Behavior, 20, 160-169.

McSweeney, F. K., \& Hinson, J. M. (1992). Patterns of responding within sessions. Journal of the Experimental Analysis of Behavior, $\mathbf{5 8}$ 19-36.

MCSweEney, F. K., Hinson, J. M., \& CAnnon, C. B. (1996). Sensitizationhabituation may occur during operant conditioning. Psychological Bulletin, 120, 256-271.

McSweeney, F. K., Kowal, B. P., \& Murphy, E. S. (2003). The effect of rate of reinforcement and time in session on preference for variability. Learning \& Behavior, 31, 225-241.

McSweeney, F. K., \& Murphy, E. S. (2000). Criticisms of the satiety hypothesis as an explanation for within-session decreases in responding. Journal of the Experimental Analysis of Behavior, 74, 347-361.

McSweeney, F. K., Murphy, E. S., \& Kowal, B. P. (2003). Dishabituation with component transitions may contribute to the interactions observed during multiple schedules. Behavioural Processes, 64, 77-89.

MCSweEney, F. K., \& Norman, W. D. (1979). Defining behavioral contrast for multiple schedules. Journal of the Experimental Analysis of Behavior, 32, 457-461.

MCSweEneY, F. K., \& Roll, J. M. (1998). Do animals satiate or habit- uate to repeatedly presented reinforcers? Psychonomic Bulletin \& Review, 5, 428-442.

MCSWEENEY, F. K., \& SWINDELl, S. (1999a). Behavioral economics and within-session changes in responding. Journal of the Experimental Analysis of Behavior, 72, 355-371.

MCSWEENEY, F. K., \& SWINDELL, S. (1999b). General-process theories of motivation revisited: The role of habituation. Psychological Bulletin, 125, 437-457.

MCSWEENEY, F. K., \& Swindell, S. (2002). Common processes may contribute to extinction and habituation. Journal of General Psychology, 129, 364-400.

MCSWEeney, F. K., SWindell, S., \& Weatherly, J. N. (1996). Withinsession changes in responding during concurrent schedules with different reinforcers in the components. Journal of the Experimental Analysis of Behavior, 66, 369-390.

MCSweeney, F. K., SwiNDEll, S., \& Weatherly, J. N. (1999). Withinsession response patterns during variable interval, random reinforcement, and extinction procedures. Learning \& Motivation, 30, 221-240.

McSweeney, F. K., \& Weatherly, J. N. (1998). Habituation to the reinforcer may contribute to multiple-schedule behavioral contrast. Journal of the Experimental Analysis of Behavior, 69, 199-221.

Melville, C. L., Rue, H. C., Rybiski, L. R., \& WeAtherly, J. N. (1997). Altering reinforcer variety or intensity changes the withinsession decrease in responding. Learning \& Motivation, 28, 609-621.

Mook, D. G. (1996). Motivation: The organization of action (2nd ed.). New York: Norton.

Palya, W. L., \& WAlter, D. E. (1997). Rate of a maintained operant as a function of temporal position within a session. Animal Learning \& Behavior, 25, 291-300.

Poucet, B., Durup, M., \& Thinus-Blanc, C. (1988). Short-term and long-term habituation of exploration in rats, hamsters and gerbils. $\underline{B e-}$ havioural Processes, 16, 203-211.

RACHLIN, H. (1973). Contrast and matching. Psychological Review, 80 217-234.

Roll, J. M., McSweeney, F. K., Johnson, K. S., \& Weatherly, J. N. (1995). Satiety contributes little to within-session decreases in responding. Learning \& Motivation, 26, 323-341.

Saulsgiver, K., Pinkston, J. W., \& Branch, M. N. (2003, May). Within-session changes during multiple variable-interval schedules. Poster presented at the meeting of the Association for Behavior Analysis, San Francisco.

Savory, C. J. (1988). Rates of eating in domestic fowls in relation to changing food deficits. Appetite, 10, 57-65.

StADDON, J. E. R. (1979). Operant behavior as adaptation to constraint. Journal of Experimental Psychology: General, 108, 349-359.

Strubbe, J. H., \& VAN DiJK, G. (2002). The temporal organization of ingestive behaviour and its interaction with regulation of energy balance. Neuroscience \& Biobehavioral Reviews, 26, 485-498.

Swithers, S. E., \& HALL, W. G. (1994). Does oral experience terminate ingestion? Appetite, 23, 113-138.

Swithers-Mulvey, S. E., Miller, G. L., \& Hall, W. G. (1991). Habituation of oromotor responding to oral infusions in rat pups. $A p$ petite, 17, 55-67.

Thompson, R. F., \& Spencer, W. A. (1966). Habituation: A model phenomenon for the study of behavior. Psychological Review, 73, 16-43.

ThOrPe, W. H. (1966). Learning and instinct in animals. Cambridge, MA: Harvard University Press.

Wagner, A. R. (1976). Priming in STM: An information-processing mechanism for self-generated or retrieval-generated depression in performance. In T. J. Tighe \& R. N. Leaton (Eds.) Habituation: Perspectives from child development, animal behavior and neurophysiology (pp. 95-128). New York: Wiley.

Williams, B. A. (1983). Another look at contrast in multiple schedules. Journal of the Experimental Analysis of Behavior, 39, 345-384.

Williams, B. A. (1991). Behavioral contrast and reinforcer value. Animal Learning \& Behavior, 19, 337-344.

(Manuscript received July 14, 2003; revision accepted for publication October 10, 2003.) 